\title{
SUR1-mutant iPS cell-derived islets recapitulate the pathophysiology of congenital hyperinsulinism
}

\author{
Väinö Lithovius ${ }^{1}$ (D) $\cdot$ Jonna Saarimäki-Vire ${ }^{1}$ (D) $\cdot$ Diego Balboa $^{1,2}$ (D) $\cdot$ Hazem Ibrahim $^{1}$ (D) $\cdot$ Hossam Montaser $^{1}$. \\ Tom Barsby ${ }^{1} \cdot$ Timo Otonkoski $^{1}$ (iD
}

Received: 18 August 2020 / Accepted: 13 October 2020 / Published online: 6 January 2021

(C) The Author(s), under exclusive licence to Springer-Verlag GmbH, DE part of Springer Nature 2021

\begin{abstract}
Aims/hypothesis Congenital hyperinsulinism caused by mutations in the $\mathrm{K}_{\mathrm{ATP}}$-channel-encoding genes $\left(\mathrm{K}_{\mathrm{ATP}} \mathrm{HI}\right)$ is a potentially life-threatening disorder of the pancreatic beta cells. No optimal medical treatment is available for patients with diazoxideunresponsive diffuse $\mathrm{K}_{\mathrm{ATP}} \mathrm{HI}$. Therefore, we aimed to create a model of $\mathrm{K}_{\mathrm{ATP}} \mathrm{HI}$ using patient induced pluripotent stem cell (iPSC)-derived islets.

Methods We derived iPSCs from a patient carrying a homozygous $A B C C 8^{\mathrm{V} 187 \mathrm{D}}$ mutation, which inactivates the sulfonylurea receptor 1 (SUR1) subunit of the $\mathrm{K}_{\mathrm{ATP}}$-channel. CRISPR-Cas9 mutation-corrected iPSCs were used as controls. Both were differentiated to stem cell-derived islet-like clusters (SC-islets) and implanted into NOD-SCID gamma mice.

Results SUR1-mutant and -corrected iPSC lines both differentiated towards the endocrine lineage, but SUR1-mutant stem cells generated $32 \%$ more beta-like cells (SC-beta cells) $(64.6 \%$ vs $49.0 \%, p=0.02)$ and $26 \%$ fewer alpha-like cells $(16.1 \%$ vs $21.8 \%$ $p=0.01)$. SUR1-mutant SC-beta cells were $61 \%$ more proliferative $(1.23 \%$ vs $0.76 \%, p=0.006)$, and this phenotype could be induced in SUR1-corrected cells with pharmacological $\mathrm{K}_{\mathrm{ATP}}$-channel inactivation. The SUR1-mutant SC-islets secreted 3.2-fold more insulin in low glucose conditions $(0.0174 \%$ vs $0.0054 \% / \mathrm{min}, p=0.0021)$ and did not respond to $\mathrm{K}_{\mathrm{ATP}}$-channel-acting drugs in vitro. Mice carrying grafts of SUR1-mutant SC-islets presented with $38 \%$ lower fasting blood glucose $(4.8 \mathrm{vs} 7.7 \mathrm{mmol} / \mathrm{l}, p=$ 0.009) and their grafts failed to efficiently shut down insulin secretion during induced hypoglycaemia. Explanted SUR1-mutant grafts displayed an increase in SC-beta cell proportion and SC-beta cell nucleomegaly, which was independent of proliferation. Conclusions/interpretation We have created a model recapitulating the known pathophysiology of $\mathrm{K}_{\mathrm{ATP}} \mathrm{HI}$ both in vitro and in vivo. We have also identified a novel role for $\mathrm{K}_{\mathrm{ATP}}$-channel activity during human islet development. This model will enable further studies for the improved understanding and clinical management of $\mathrm{K}_{\mathrm{ATP}} \mathrm{HI}$ without the need for primary patient tissue.
\end{abstract}

Keywords Beta cells $\cdot$ Congenital hyperinsulinism $\cdot$ Disease modelling $\cdot$ Induced pluripotent stem cells $\cdot \mathrm{K}_{\mathrm{ATP}}$-channel . Pancreatic islet development $\cdot$ Stem cell-derived islets

$\begin{array}{llll}\begin{array}{l}\text { Abbreviations } \\ \text { CHI }\end{array} & \text { Congenital hyperinsulinism } & \mathrm{K}_{\mathrm{ATP}} \mathrm{HI} & \begin{array}{l}\text { Congenital hyperinsulinism due } \\ \text { to loss-of-function of the } \mathrm{K}_{\mathrm{ATP}} \text { channel }\end{array} \\ \text { CXCR4 } & \text { C-X-C motif chemokine receptor 4 } & \text { PDX1 } & \begin{array}{l}\text { Pancreatic and duodenal homeobox 1 } \\ \text { GBC }\end{array} \\ \text { iPSC } & \text { Glibenclamide } & \text { RNP } & \text { Ribonucleoprotein } \\ & \text { Induced pluripotent stem cell } & \text { SC-alpha cell } & \text { Stem cell-derived alpha-like cell }\end{array}$

Väinö Lithovius

vaino.lithovius@helsinki.fi

Timo Otonkoski timo.otonkoski@helsinki.fi
Stem Cells and Metabolism Research Program in the Faculty of Medicine of the University of Helsinki, Helsinki, Finland

2 Present address: Bioinformatics and Genomics Program, Centre for Genomic Regulation (CRG), The Barcelona Institute of Science and Technology (BIST), Barcelona, Spain 


\section{Research in context}

\section{What is already known about this subject?}

- Loss of Katp-channel activity leads to constitutive insulin secretion from beta cells and is the leading genetic cause of congenital hyperinsulinism (KATPHI)

- Previous models using KATP-channel gene knockout mouse strains have demonstrated a milder phenotype than is observed in human patients

- In addition to constitutive insulin secretion, beta cells of $\mathrm{K}_{\mathrm{ATP}} \mathrm{HI}$ patients display increased proliferation and a higher occurrence of nucleomegaly

What is the key question?

- Can these features of $\mathrm{K}_{\mathrm{ATP}} \mathrm{HI}$ be replicated in a model based on stem cell-derived islets?

\section{What are the new findings?}

- Excessive secretion of insulin seen in $\mathrm{K}_{\mathrm{ATPH}} \mathrm{HI}$ can be recapitulated both in vitro and in vivo using patient induced pluripotent stem cell-derived islets

- More subtle features of the disease phenotype, such as increased proliferation and nucleomegaly, are also recapitulated in the model

- Loss of KatP-channel activity leads to increased beta cell mass in in vitro differentiation

How might this impact on clinical practice in the foreseeable future?

- This work establishes a platform that can be used to screen novel treatments for $\mathrm{K}_{\text {ATPHI }}$

SC-beta cell Stem cell-derived beta-like cell

SC-islet Stem cell-derived islet-like cluster

SUR1 Sulfonylurea receptor 1

\section{Introduction}

Congenital hyperinsulinism (CHI) defines disorders of pancreatic beta cells characterised by hypoglycaemia caused by inappropriate insulin secretion. Pancreatic beta cells regulate blood glucose by linking their intracellular glucose metabolism with insulin secretion via the $\mathrm{K}_{\mathrm{ATP}}$-channel [1]. Inactivating mutations in the beta cell $\mathrm{K}_{\mathrm{ATP}}$-channel genes are the most common cause of $\mathrm{CHI}\left(\mathrm{K}_{\mathrm{ATP}} \mathrm{HI}\right)$, comprising $36-61 \%$ of all cases $[2,3]$. In $\mathrm{K}_{\mathrm{ATP}} \mathrm{HI}$, the $\mathrm{K}_{\mathrm{ATP}}$-channels are either insensitive to the changes in intracellular ATP/ ADP ratio, or they are missing from the plasma membrane. This leads to constant membrane depolarisation and constant influx of calcium through the voltage-gated calcium channels, resulting in constitutive insulin secretion from the beta cells. [4-6]. Thus, $\mathrm{K}_{\mathrm{ATP}} \mathrm{HI}$ typically presents as persistent, severe neonatal hypoglycaemia. The major histological type of $\mathrm{K}_{\mathrm{ATP}} \mathrm{HI}$ is recessively inherited diffuse $\mathrm{K}_{\mathrm{ATP}} \mathrm{HI}$, in which all beta cells are affected. $\mathrm{K}_{\mathrm{ATP}}$-channel-activating diazoxide is used as the first-line CHI therapy. However, due to the lack of the $\mathrm{K}_{\mathrm{ATP}}$-channel activity, patients with diffuse $\mathrm{K}_{\mathrm{ATP}} \mathrm{HI}$ are in most cases resistant to this therapy $[4,7]$. Therapy with nonspecific second-line drugs, such as octreotide and nifedipine, or with frequent feeding is then attempted. However, up to $55 \%$ of the $\mathrm{K}_{\mathrm{ATP}} \mathrm{HI}$ patients remain without adequate glycaemic control using these treatments, requiring neartotal pancreatectomy [8]. Pancreatectomy acutely results in euglycaemia in only $31 \%$ of the patients [9] with $91-96 \%$ of the patients developing diabetes in long-term follow-up [10, 11]. The currently suboptimal management of diffuse $\mathrm{K}_{\mathrm{ATP}} \mathrm{HI}$ highlights the need for novel therapies.

Islet material from CHI patients is extremely scarce and $\mathrm{K}_{\mathrm{ATP}}$-channel knockout mouse studies have not fully recapitulated the severity of the human phenotype [12-15], and both these issues have hindered the study of CHI pathophysiology and pharmaceutical development needed for improved patient care.

The advent of induced pluripotent stem cell (iPSC) technology has allowed the limitless expansion of stem cells carrying the patient mutation [16, 17]. CRISPR-Cas9 genome editing [18] has made it possible to efficiently correct specific mutations in order to generate isogenic cell lines that are discordant only for the mutation of interest $[19,20]$. Differentiating human embryonic stem cells with a $\mathrm{K}_{\mathrm{ATP}} \mathrm{HI}$ mutation in $2 \mathrm{D}$ towards beta-like cells has been previously shown to replicate the insulin hypersecretion phenotype in vitro [21]. 
Our objective was to create an improved model of $\mathrm{K}_{\mathrm{ATP}} \mathrm{HI}$ by using a 2D-to-3D protocol [20] to differentiate sulfonylurea receptor 1 (SUR1)-mutant patient iPSCs into stem cellderived islets ( $\mathrm{SC}$-islets) and implanting them into mice to encompass the disease phenotype both in vivo and in vitro. Additionally, we studied the effect of $\mathrm{K}_{\mathrm{ATP}}$-channel inactivation on islet differentiation.

\section{Methods}

Derivation of the iPSC lines The patient iPSC line HEL113.5 was derived from a $\mathrm{K}_{\mathrm{ATP}} \mathrm{HI}$ patient carrying a homozygous c.560T $>$ A (V187D) mutation in the exon 4 of the $A B C C 8$ gene encoding the SUR1 protein [6]. It was derived at the Biomedicum Stem Cell Center, University of Helsinki, from donated skin fibroblasts with a Sendai virus (SeVdp) vector carrying the reprogramming factors octamer-binding transcription factor (OCT)3/4, Krüppel-like factor 4 (KLF4), SRY (sex determining region Y)-box 2 (SOX2) and c-Myc. The healthy control cell line HEL46.11 [22] was derived similarly. The Coordinating Ethics Committee of the Helsinki and Uusimaa Hospital District (no. 423/13/03/00/08) approved the patient informed consent for the derivation of the hiPSC lines used in this study.

Correction of the mutation in the patient iPSC line Guide RNA (TCGTGGAGGTCAATGTCATC-AGG) targeting the $A B C C 8$ gene V187D mutation site was designed using a webbased tool, Benchling (https://benchling.com, accessed 1 Feb 2018), with cut site $8 \mathrm{bp}$ from the mutation. To perform the genome editing in the HEL113.5 cell line, guide RNA was used together with Cas9 in a complexed ribonucleoprotein (RNP).

The RNP complex was delivered by electroporation using the Neon Transfection System (ThermoFisher, USA) to 2 million Accutase (ThermoFisher, cat.no. A11105-01) dissociated HEL113.5 cells, together with $2 \mu \mathrm{l}$ of a $100 \mu \mathrm{mol} / 1$ solution of electroporation enhancer (IDT, USA, cat.no. 1075915), $2 \mu \mathrm{g}$ of pCXLE-mp53DD plasmid (Addgene no. 41859 ) and $2 \mu \mathrm{g}$ of donor template, as described elsewhere [20]. Limited dilution cloned colonies were screened using PCR followed by HincII restriction. Recombinant colonies were validated using Sanger sequencing and checked for chromosomal abnormalities by G-banding karyotyping. Absence of pCXLE-mp53DD plasmid was determined using PCR for plasmid EBNA and ORIP backbone sequences. Full sequences for the PCR primers and correction template are available in the electronic supplementary material (ESM) Methods.

Cell culture Mycoplasma-free iPSCs were maintained on Matrigel-coated plates in Essential 8 (E8) medium (Thermo Fisher, cat.no. A1517001). The differentiation was carried out essentially as described previously [20] with a protocol modified from key publications [23-26]. The complete protocol is available in the ESM Methods. In brief, the iPSCs were dissociated and seeded on Matrigel-coated plates in E8 to create a confluent monolayer. Differentiation was initiated $24 \mathrm{~h}$ later by changing to the stage 1 medium. Differentiations that failed to achieve $>90 \%$ positivity for $\mathrm{C}-\mathrm{X}-\mathrm{C}$ motif chemokine receptor 4 (CXCR4) at the end of stage 1 were aborted. After the pancreatic progenitor stage, stage 4 , the cells were dissociated with TrypLE (ThermoFisher, cat.no. 12563029), and they were allowed to spontaneously aggregate in suspension on plates placed on a rotating platform.

In some experiments, $0.1 \mu \mathrm{mol} / 1$ glibenclamide (GBC) (Tocris, UK, cat. no. 0911) was added to inactivate the $\mathrm{K}_{\mathrm{ATP}}$-channels during stages 5,6 and 7. An equal volume of DMSO was added to the control wells.

Flow cytometry A single cell suspension was created by dissociating the cells with TrypLE. For definitive endoderm (stage 1) flow cytometry, the cells were stained directly for $30 \mathrm{~min}$ in room temperature with CXCR4 antibody in $100 \mu \mathrm{lBS}+5 \%$ FBS and analysed the same day. For pancreatic progenitor (stage 4) flow cytometry, the cells were fixed for $20 \mathrm{~min}$ with Cytofix/Cytoperm (BD Biosciences, USA, cat.no. 554714), and stained overnight in $+4{ }^{\circ} \mathrm{C}$ with NKX6.1 and pancreatic and duodenal homeobox 1 (PDX1) antibodies in $100 \mu \mathrm{l}$ Perm/Wash (BD Biosciences, cat.no. 554714) +5\% FBS. The samples were run with FACSCalibur flow cytometer (BD Biosciences). The data were analysed with FlowJo software v10 (FlowJo, USA). After filtering the debris using FSC/SSC gating, the gating for the positive cells was done using isotype controls when the populations were not clearly separated and when they were, the gate was placed in the midpoint between the positive and negative peaks. Antibody details are available in ESM Table 1.

In vitro tests of insulin secretion One hundred $\mathrm{SC}$-islets were hand-picked on stage 7 day 5-9, washed and preincubated in $\mathrm{KRB}$ with $3.3 \mathrm{mmol} / \mathrm{l}$ glucose for $1-2 \mathrm{~h}$. Multi-step tests were carried out in sequence on the same SC-islets in KRB. Full test protocols are available in the ESM Methods.

SC-islet implantation Implantation of SC-islets under the kidney capsule of male and female NOD-SCID-gamma mice (Jackson laboratories strain no. 005557) was performed as previously described [19]. In brief, approximately 1000 stage 7 SC-islets were compacted into PE-50 tubing and implanted into the exposed left kidney with a syringe (Hamilton, USA, ref.no. 81301). Animals from each litter were randomised to receive a SUR1-mutant or a healthy graft (non-isogenic control or SUR1-corrected graft). Further details are available in the ESM Methods and ESM Table 2. 
Insulin tolerance test and graft explantation Four months after the implantation, the mice were subjected to an insulin tolerance test. The mice were fasted for $5 \mathrm{~h}$, a baseline blood glucose measurement (Lifescan, USA, OneTouch ultra) and a $75 \mu$ l blood sample from the saphenous vein was obtained. Then, $0.75 \mathrm{IU} / \mathrm{kg}$ of human insulin analogue (Novo Nordisk, Denmark Actrapid) was administered intraperitoneally. Blood glucose was measured at 20, 40 and $60 \mathrm{~min}$ and another $75 \mu \mathrm{l}$ blood sample obtained at $40 \mathrm{~min}$ post injection. Human specific C-peptide was measured from the serum samples with ELISA assay (Mercodia, Sweden). After the test, the mice were euthanised in a $\mathrm{CO}_{2}$ chamber, rapidly dissected and the kidneys containing the grafts fixed in $4 \%$ PFA for 2 days.

Immunohistochemistry and slide imaging The SC-islet samples were taken on stage 7 day 6-8, fixed for $2 \mathrm{~h}$ in $4 \%$ PFA, embedded in paraffin, cut into $5 \mu \mathrm{m}$ sections, subjected to heat-induced epitope retrieval in $0.1 \mathrm{~mol} / 1$ citrate buffer, immunostained and then imaged with the Zeiss (Germany) Axio Observer Z1 using the Apotome 2 as previously described [20]. Sections that would be later compared were imaged using the same settings and exported with the same intensity scaling. Antibody details are available in the ESM Table 1.

\section{Morphometric analyses of stage 7 SC-islets and explanted 4-} month grafts Immunostainings were quantified using a custom image analysis pipeline on CellProfiler 3.0 [27] (https://cellprofiler.org). First, nuclei were identified from the image displaying the DNA signal. The locations of the nuclei were then used as seeds to be propagated along the intensity gradient of the insulin or glucagon signal to identify the cytoplasm. Speckles of $<50 \mathrm{px}^{2}$ were excluded. If $>50 \%$ of insulin-positive cytoplasm was covered by glucagon-positive cytoplasm, the cells were considered to co-stain. To obtain accurate cell counts even if the cytoplasm was fragmented, the overlap of nuclear border on the surrounding cytoplasm was compared. If $>15 \%$ of the nuclear border was surrounded by insulin, glucagon or co-staining cytoplasm the nucleus was counted positive for that marker. The final data are based on the counts of these nuclei and not fragments of cytoplasm. To identify Ki-67- and TUNELpositive cells, the pipeline was configured to create images displaying borders of nuclei assigned to insulin-positive cells on the Ki-67 or TUNEL signal containing image. The colocalisation was manually verified from these images. Thresholds were set manually and the same pipeline settings were used in the comparable SUR1-mutant- and SUR1corrected samples in effect making the analysis blinded.

Statistical analyses and data collection PRISM 8.0 (Graph Pad software, CA, USA) was used for statistical analyses. Statistical methods for each analysis are listed in figure legends. SUR1-corrected and healthy donor iPSC-derived $\mathrm{SC}$-islets were pooled together for analyses of in vitro and in vivo function, but displayed with separate symbols on graphs. Numbers in the main text are mean values unless otherwise indicated. All data points represent independent observations: differentiation experiments, animals, explanted grafts or individual cells. All data points are visible on the graphs, except in Fig. 5e. Researchers were not blinded to the genotype of the samples except when conducting the morphometric analyses. Littermate control animals were randomly assigned to receive grafts of the different genotypes used, but randomisation was not used in other stages of the study.

\section{Results}

SUR1 mutation correction with CRISPR-Cas9 in patient iPSC The iPSC line HEL113 was derived from a $\mathrm{K}_{\mathrm{ATP}} \mathrm{HI}$ patient carrying a homozygous c.560 $\mathrm{T}>\mathrm{A}$ (V187D) mutation in the exon 4 of the $A B C C 8$ gene encoding the SUR1 protein [6]. To allow reliable conclusions concerning the impact of the mutation, we corrected the V187D-mutation with CRISPR-Cas9 (Fig. 1b), yielding four homozygously corrected clones (Fig. 1c). These clones were validated using Sanger sequencing and karyotyping, presenting correction of the mutation, no chromosomal abnormalities, and no remnants of coelectroporated plasmid sequence (Fig. 1c, ESM Fig. 1a,b,c). Upon stem cell culture, clone number 1 displayed a higher rate of proliferation and abnormal morphology compared with the parental and sister clones and was excluded from further analyses.

\section{SUR1 mutation leads to increased beta cell proliferation and} mass in SC-islets We differentiated the iPSCs towards beta cells using a previously published 7-stage protocol (Fig.1a) [20]. The efficiency of each differentiation experiment was studied at the end of the definitive endoderm induction (stage 1 of the differentiation) and the pancreatic progenitor formation (stage 4) with flow cytometry. SUR1-mutant and SUR1corrected cells had similar proportions of $\mathrm{CXCR}^{+}$cells at stage 1 (median $97.1 \%$ vs $94.4 \%, p=0.31$ ) (ESM Fig. 2a) and $\mathrm{PDX} 1^{+} \mathrm{NKX} 6.1^{+}$cells (median $78.1 \%$ vs $76.9 \%, p=$ 0.57) (ESM Fig. 2b) at stage 4. Thus demonstrating that the mutation did not affect the development of endodermal or pancreatic progenitors.

To study how the SUR1 mutation affects islet endocrine cell mass, we quantified the populations of cells positive for insulin (SC-beta cells), glucagon (SC-alpha cells) or both of these hormones in immunohistochemical sections of SC-islets at the end of the differentiation protocol (stage 7), using a custom automated segmentation pipeline (Fig. 2a). SUR1mutant SC-islets contained $32 \%$ more SC-beta cells $(64.6 \%$ vs $49.0 \%, p=0.02$ ), an equal number of cells positive for both 
insulin and glucagon ( $4.9 \%$ vs $5.5 \%, p=0.45)$ and $26 \%$ fewer SC-alpha cells $(16.1 \%$ vs $21.8 \% p=0.01)$ (Fig. $2 b)$ than the SUR1-corrected SC-islets. The sum of these three distinct endocrine populations was higher in the SUR1-mutant SCislets (76.2\% vs $65.2 \%, p=0.02)$ (ESM Fig. 2c).

Proliferation has previously been found to be increased in diffuse $\mathrm{K}_{\text {ATP }}$-HI patient beta cells [28-32], and could contribute to the increased number of insulin-positive cells we detected in the SC-islets. We therefore examined the expression of the proliferation marker Ki-67 using immunohistochemistry (Fig. 2c). The SUR1-mutant SC-beta cells co-stained more frequently with Ki-67 than the SUR1-corrected SC-beta cells $(1.23 \%$ vs $0.76 \%, p=0.006)$ (Fig. 2 d, ESM Fig. 2e). To confirm that the increased proliferation was dependent on $\mathrm{K}_{\mathrm{ATP}}$-channel inactivation, we treated the cells with GBC, a drug which inactivates the $\mathrm{K}_{\mathrm{ATP}}$ channel, throughout endocrine cell formation and maturation (stages 5-7). Upon addition of GBC, the proportion of proliferative SC-beta cells in SUR1-corrected SC-islets increased to $1.10 \%$ (from $0.76 \%$, $p=0.03$ ) (Fig. 2d, ESM Fig. 2d). The proliferation rate of non-SC-beta cells was higher than that of the SC-beta cells (around 1.6\%), but neither genotype nor GBC treatment had an effect on the proliferation rate of these cells (ESM Fig. 2e).

\section{SUR1-mutant SC-islets have higher insulin secretion in low} glucose and fail to respond to $\mathrm{K}_{\mathrm{ATP}}$-channel acting pharmaceuticals Next, we studied the in vitro function of the SC- islets using sequential static incubations, to assess whether our model replicates the hypersecretion of insulin seen in $\mathrm{K}_{\mathrm{ATP}} \mathrm{HI}$ patient islets in vitro [4]. The SUR1-mutant SC-islets secreted 3.2-fold more of their insulin content in low glucose $(3.3 \mathrm{mmol} / \mathrm{l})$ compared with SUR1corrected controls $(0.0174 \% / \mathrm{min}$ vs $0.0054 \% / \mathrm{min} p=$ 0.0021) (Fig. 3a, ESM Fig. 3a,b). Treatment of SUR1corrected SC-islets with GBC through stages 5, 6 and 7 rendered them hypersecretory as their secretion was increased 2.6-fold compared with DMSO treatment $(0.0140 \% / \mathrm{min}$ vs $0.0054 \% / \mathrm{min}, p=0.0063)$, despite GBC having been washed out $1 \mathrm{~h}$ prior to the test (Fig. 3a). Both SUR1-mutant and SUR1-corrected SC-islets (analysed together with healthy non-isogenic SC-islets) were unresponsive to high glucose (Fig. 3b) indicating $\mathrm{SC}$-islets derived using this protocol lack mature stimulation-secretion coupling. These healthy $\mathrm{SC}$-islets responded to the first-line $\mathrm{CHI}$ treatment, $\mathrm{K}_{\mathrm{ATP}}$-channel opener diazoxide by a $56 \%$ reduction and to the $\mathrm{K}_{\mathrm{ATP}}{ }^{-}$ channel-closing sulfonylurea drug tolbutamide by a $54 \%$ increase of insulin secretion, while neither had effect on the SUR1-mutant SC-islets (Fig. 3b).

To study whether the SUR1-mutant SC-islets are responsive to non- $\mathrm{K}_{\mathrm{ATP}}$-channel-dependent modulators of insulin secretion, we exposed them to the glucagon-like peptide 1 (GLP1)-receptor agonist exendin-4, alpha 2 -adrenoceptor agonist clonidine and to sequestration of extracellular $\mathrm{Ca}^{2+}$

a

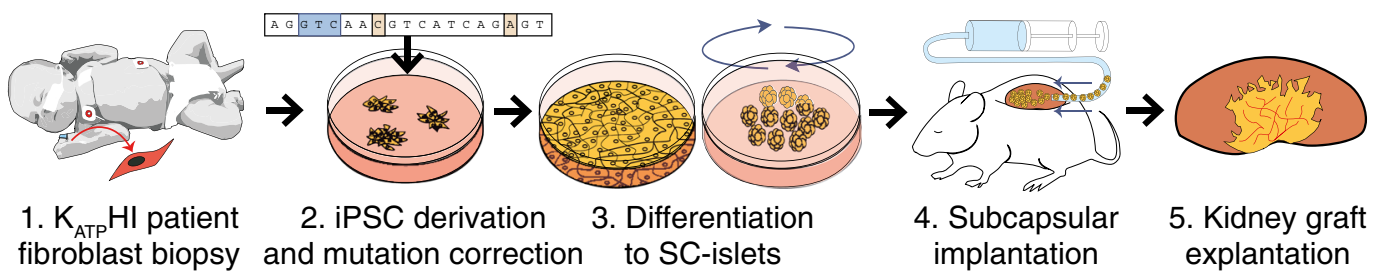

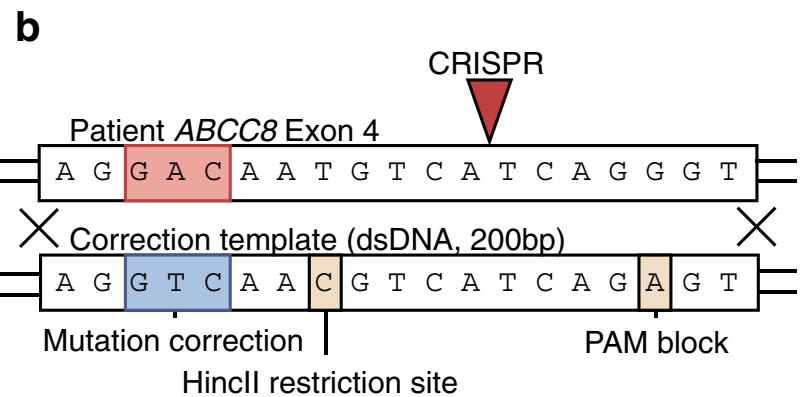

Hincll restriction site

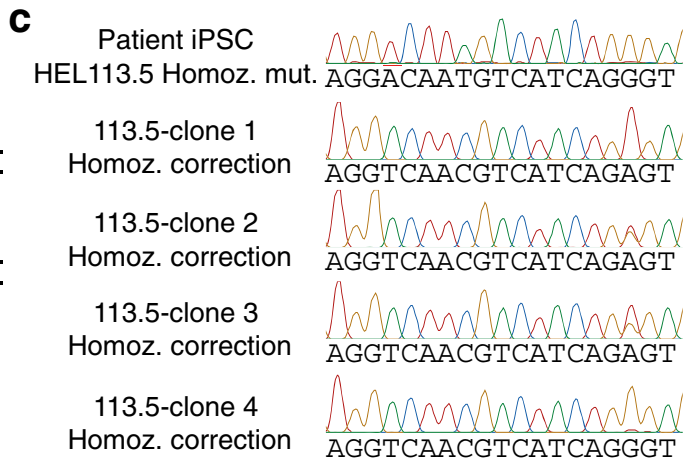

Cas9 from cutting the correction template. (c) Sequencing of the parent clone with the homozygous (Homoz.) $A B C C 8^{\mathrm{V} 187 \mathrm{D}}$ SUR1 mutation and the four homozygously corrected clones. The mouse image in (a) is adapted from Gwilz/Wikimedia Commons under a Creative Commons Attribution-Share Alike 4.0 International license; the baby image is from pixabay.com 

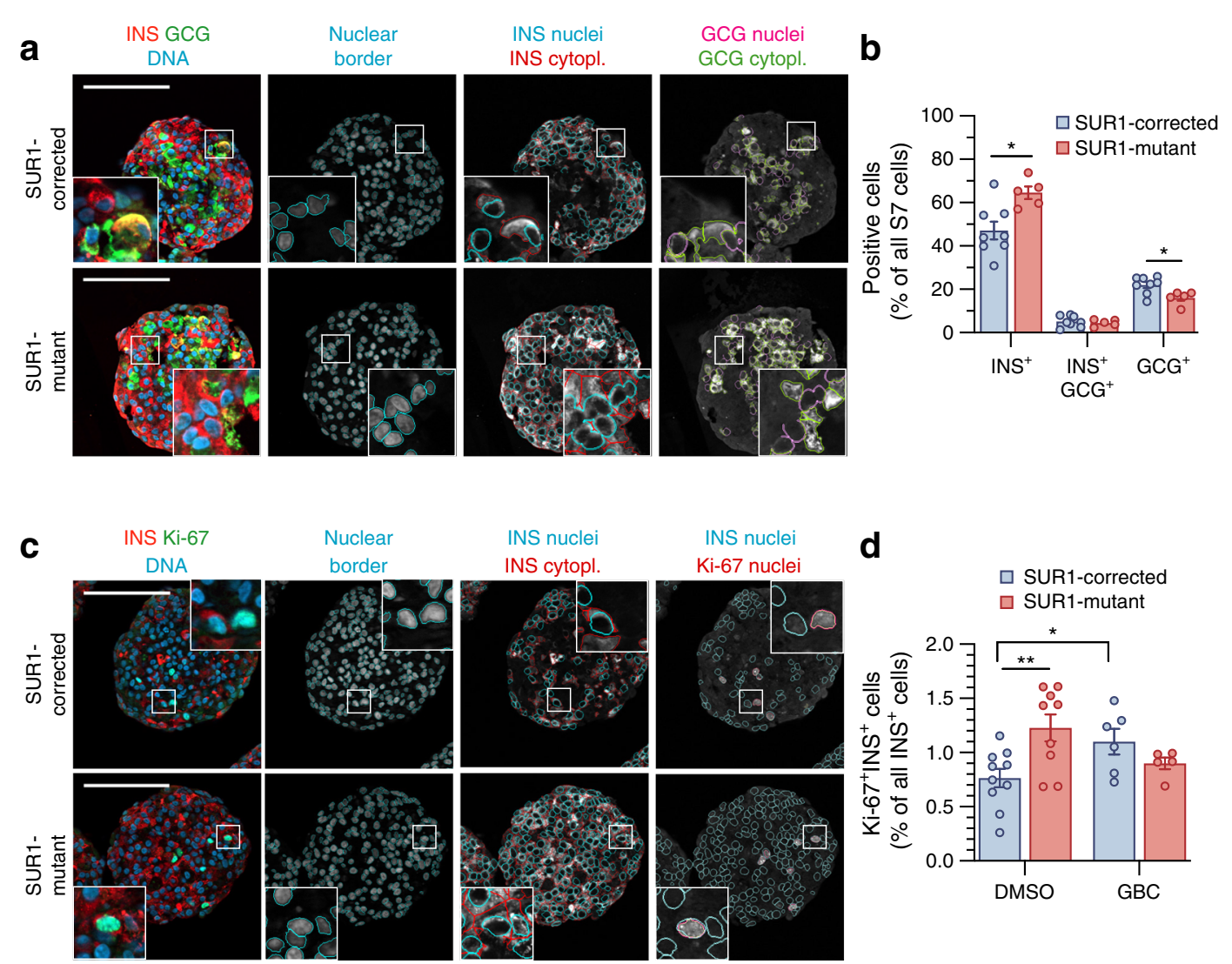

Fig. 2 SUR1-mutant SC-islets contain more insulin-positive cells. (a) Characterisation of stage 7 SC-islets with insulin-glucagon-DNA immunohistochemistry, along with quality control output images produced by the automatic segmentation pipeline, displaying nuclear segmentation and identification of insulin (INS) and glucagon (GCG) positive cytoplasm (cytopl.) and assigning of nuclei to the corresponding cytoplasm. Scale bars, $100 \mu \mathrm{m}$. Insets show $3 \times$ magnification. (b) Quantification of insulin-glucagon immunohistochemistry. (c) Characterisation of stage 7 (S7) SC-islets with insulin-Ki-67-DNA immunohistochemistry, and quality control output images, displaying nuclear segmentation,

by EGTA. SUR1-corrected SC-islets increased insulin secretion by $50 \%$ in response to exendin- 4 in the presence of high glucose (Fig. 3d), but not in low glucose (Fig. 3c); SUR1mutant SC-islets remained unresponsive to exendin-4 regardless of glucose concentration. Both clonidine and EGTA inhibited insulin secretion by $40-50 \%$ compared with the baseline secretion in low glucose, an effect equal in both SUR1-mutant and SUR1-corrected SC-islets (Fig. 3c).

The insulin content of the SC-islets was analysed after these tests. There were no differences in the insulin content between SUR1-mutant and SUR1-corrected SC-islets nor GBC- and DMSO-treated SC-islets (ESM Fig. 3c).

\section{Grafts of SUR1-mutant SC-islets cause hyperinsulinaemic} hypoglycaemia in vivo To create an in vivo model of $\mathrm{K}_{\mathrm{ATP}} \mathrm{HI}$, we implanted SUR1-mutant, SUR1-corrected and healthy nonisogenic SC-islets into the kidney subcapsular space of immunocompromised mice. Four months after engraftment, we subjected identification of insulin signal and identification of $\mathrm{Ki}-67$ positive nuclei. Scale bars, $100 \mu \mathrm{m}$. Insets show $3 \times$ magnification. (d) Quantification of insulin-Ki-67 immunohistochemistry. GBC indicates GBC treatment $100 \mathrm{nmol} / 1$ during stages 5, 6 and 7; DMSO was used as the vehicle control. (b, d) Analysis by Welch's unequal variances $t$ test: $* p<0.05$; ** $p<0.01$. Data presented as mean \pm SEM, pooled data from 2 SURmutant (red bars) and 3 SUR-corrected clones (blue bars). Each data point represents population-wide characteristics of an independent differentiation experiment

the mice to a $5 \mathrm{~h}$ fast and an immediate insulin tolerance test. The SUR1-mutant-grafted mice exhibited 38\% lower fasting blood glucose ( $4.8 \mathrm{vs} 7.7 \mathrm{mmol} / \mathrm{l}, p=0.009$ ), reaching hypoglycaemic ( $<3.3 \mathrm{mmol} / \mathrm{l})$ levels in 3/9 of the SUR1-mutant-grafted mice (Fig. 4a); this was in conjunction with 6.7-fold higher levels of circulating human C-peptide, when compared with the pooled SUR1-corrected and healthy non-isogenic SC-islet grafted mice (901 vs $135 \mathrm{pmol} / 1, p<0.0001$ ) (Fig. 4b). We then challenged the mice with exogenous insulin to study the graft function in hypoglycaemic conditions. Critically, the circulating C-peptide levels in the SUR1-mutant-grafted mice remained high after the insulin injection, being approximately 16.4 -fold higher than in the healthy controls ( $627 \mathrm{vs} 38.2 \mathrm{pmol} / \mathrm{l}$, at $40 \mathrm{~min}, p<0.0001$ ) (Fig. 4b), despite $7 / 9$ of the mice being hypoglycaemic ( $<3.3 \mathrm{mmol} / \mathrm{l}$ blood glucose). C-peptide levels before and after the insulin injection showed that the healthy grafts reduced their C-peptide secretion by $67 \%$, whereas the reduction was $30 \%$ in the SUR1-mutant grafts $(p=0.009)$ (Fig. 4c). 


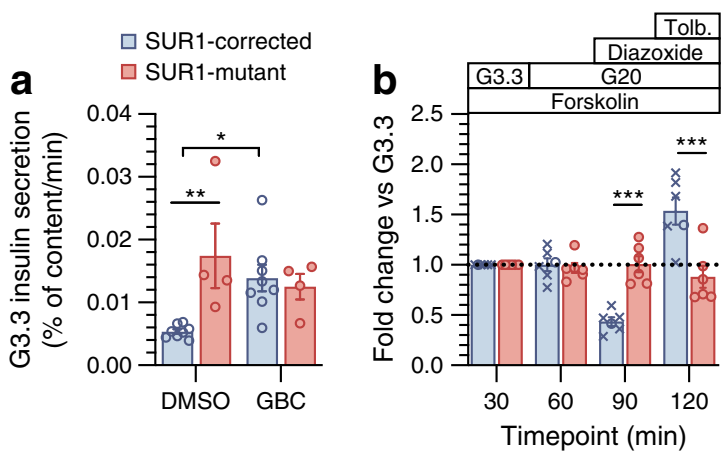

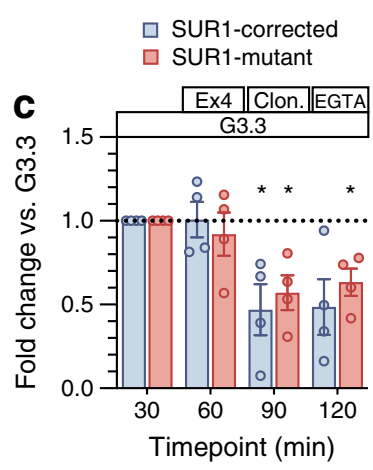

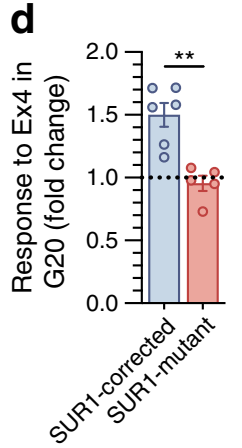

Fig. 3 SUR1-mutant SC-islets are hypersecretory and unresponsive to $\mathrm{K}_{\mathrm{ATP}}$-channel-acting drugs. (a) Insulin secretion during $1 \mathrm{~h}$ incubation in $3.3 \mathrm{mmol} / 1$ glucose (G3.3). Some SC-islets were treated with GBC $(100 \mathrm{nmol} / \mathrm{l})$ through stages 5 to 7 . GBC was washed out $1 \mathrm{~h}$ before the test. DMSO was used as the vehicle control. Analysis by two-way ANOVA. (b) Sequential static incubation responses to $20 \mathrm{mmol} / \mathrm{l}$ glucose (G20), diazoxide $(100 \mu \mathrm{mol} / \mathrm{l})$ and tolbutamide (Tolb., $100 \mu \mathrm{mol} / \mathrm{l})$. Analysis by two-way ANOVA. (c) Sequential static incubation responses to exendin-4 (Ex4, $50 \mathrm{ng} / \mathrm{ml})$, clonidine (Clon., $2 \mu \mathrm{mol} / \mathrm{l})$ and EGTA (100 $\mu \mathrm{mol} / \mathrm{l})$ in $3.3 \mathrm{mmol} / \mathrm{l}$ glucose. Analysis by one-sample $t$ test vs a value of
1.0. (d) Fold increase in response to exendin- 4 treatment in $20 \mathrm{mmol} / \mathrm{l}$ glucose vs $20 \mathrm{mmol} / 1$ alone. Analysis by Welch's unequal variances $t$ test. Data presented as mean \pm SEM, from SUR1-mutant clones (red bars), SUR1-corrected clones (blue bars, circles) and healthy donor iPSCs (blue bars, crosses). (a) 2 mutant and 3 corrected clones (b) 1 mutant, 1 corrected clone and 1 healthy donor iPSC clone. (c, d) 1 mutant and 1 corrected clone. Each data point represents an SC-islet sample from an independent differentiation experiment. $* p<0.05$; $* * p<0.01$; $* * * p<0.001$, as indicated, and by analysis as detailed above

\section{Increased beta cell proportion in engrafted SUR1-mutant SC-} islets is maintained in vivo After the insulin tolerance test at 4 months post engraftment, the grafts were explanted and analysed with immunohistochemistry to observe whether the changes in hormonal cell populations and proliferation marker expression were also present in vivo (Fig. 5a). Analysis of the insulin- and glucagon- immunoreactive cells revealed that a larger proportion of the hormone-positive cells in the SUR1-mutant grafts were insulin positive $(71.5 \%$ vs $55 \% p=0.06)$ and a smaller proportion glucagon positive ( $18.9 \%$ vs $36.9 \% p=0.005)$ compared with the SUR1-corrected grafts (Fig. 5b). The proportion of cells co-expressing insulin and glucagon was equally low in SUR1-mutant and -corrected grafts $(3.3 \%$ vs $2.7 \% p=0.81)$
(Fig. 5b). SUR1-mutant insulin-positive cells no longer expressed Ki-67 more frequently than the SUR1-corrected insulin-positive cells (Fig. 5c).

The disease progression in diffuse $\mathrm{K}_{\mathrm{ATP}} \mathrm{HI}$ patients is often self-limiting as insulin secretion reduces over time and many develop diabetes over long-term follow-up. Apoptosis of the hyperactive beta cells could contribute to this self-limitation and thus we examined it in our 4-month material using TUNEL as a marker. However, the overall rate of insulinTUNEL co-expression was low and not significantly different between SUR1-corrected and SUR1-mutant grafts (4 out of 17,961 vs 8 out of 25,598 SC-beta cells, respectively) (ESM Fig. 4).

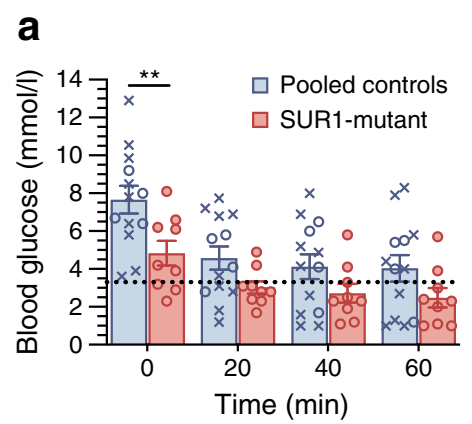

Fig. 4 Hyperfunctionality of SUR1-mutant SC-islet grafts at 4 months after engraftment. (a) Mouse blood glucose after a $5 \mathrm{~h}$ fast $(0 \mathrm{~min})$ and after an insulin injection (20, 40 and $60 \mathrm{~min})$. Measurements $<1 \mathrm{mmol} / 1$ are marked as $1 \mathrm{mmol} / \mathrm{l}$. Horizontal line at $3.3 \mathrm{mmol} / 1$ to mark hypoglycaemic level of blood glucose. (b) Human specific C-peptide at fasted (0 min) and insulin-challenged conditions (40 min). (c) Human C-
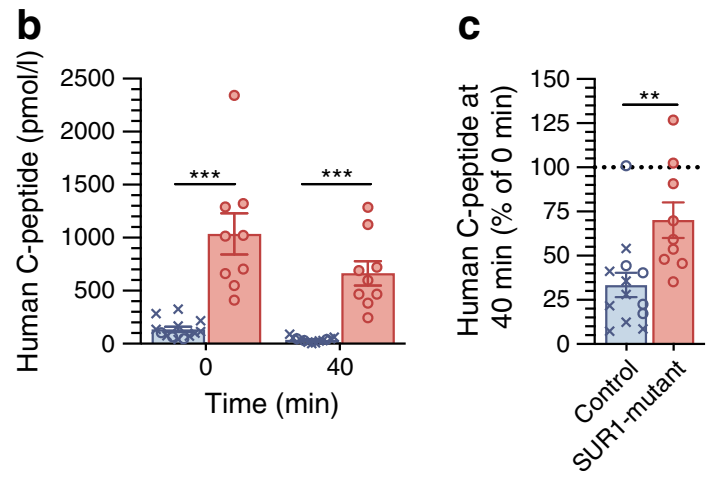

peptide secretion at $40 \mathrm{~min}$, relative to $0 \mathrm{~min}$. (a, c) Analysis by Welch's unequal variances $t$ test; (b) Two-way ANOVA: $* * p<0.01$; $* * * p<0.001$. Data presented as mean \pm SEM, from one SUR1-mutant clone (red bars), one SUR1-corrected clone (blue bars, circles) and one healthy donor iPSC clone (blue bars, crosses). Each data point represents measurements from an individual animal 

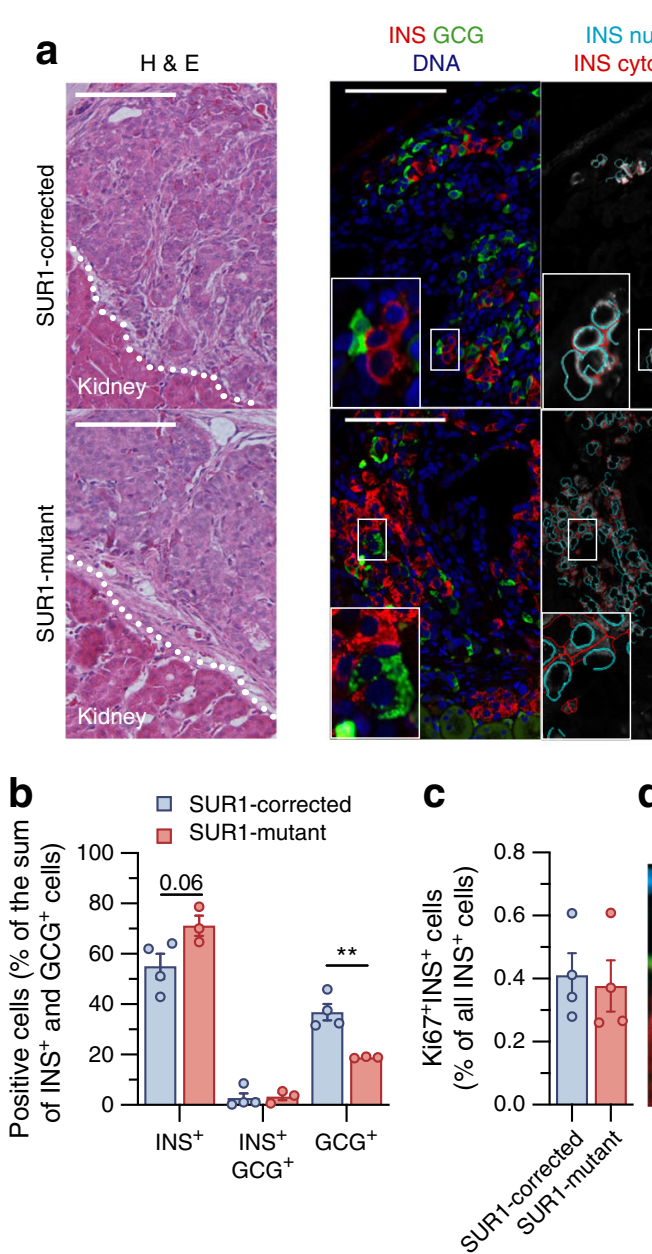

d
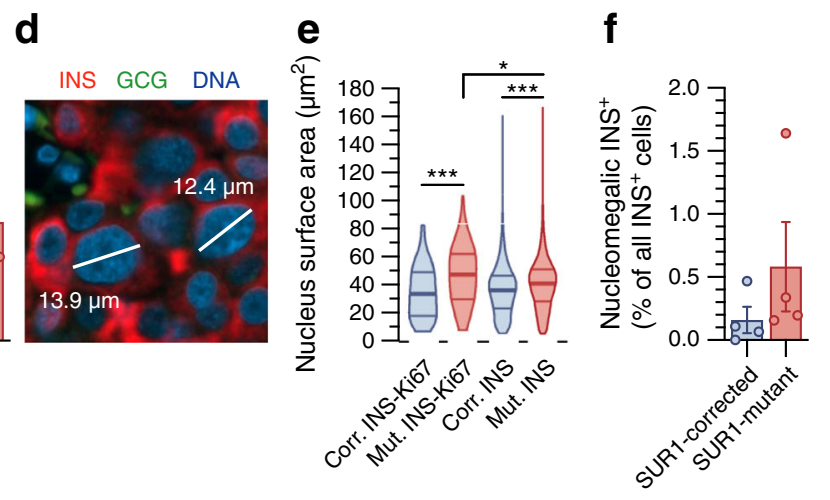

Fig. 5 SC-islet grafts explanted at 4 months display a higher proportion of insulin-positive cells with sporadic nucleomegaly. (a) Characterisation of explanted SC-islet grafts, showing H\&E staining; insulin (INS)-glucagon (GCG)-DNA immunohistochemistry and associated analysis images displaying the cytoplasms (cytopl.) and nuclei assigned to the cytoplasms; and insulin-Ki-67-DNA immunohistochemistry and associated analysis image displaying nuclei assigned to insulin-positive cytoplasms and $\mathrm{Ki}$ 67-positive nuclei (white arrows). Scale bars $100 \mu \mathrm{m}$. (b) Quantification of insulin-glucagon immunohistochemistry; each individual population (INS $\mathrm{GCG}^{-}, \mathrm{INS}^{+} \mathrm{GCG}^{+}$and $\mathrm{INS}^{-} \mathrm{GCG}^{+}$) was compared with the sum of the populations. (c) Quantification of insulin-Ki-67 immunohistochemistry: \% of insulin-positive cells that co-stain with Ki-67. (d) Example of abnormally large nuclei present in SUR1-mutant grafts, with nuclear

Additionally, we noticed a subpopulation of SC-beta cells with strikingly large nuclei (Fig. 5d) in the SUR1mutant grafts. This nucleomegaly is observed in most islet specimens from $\mathrm{K}_{\mathrm{ATP}} \mathrm{HI}$ patients, and rarely in healthy islets [33]. To characterise this phenomenon further, we quantified the surface area of all SC-beta cell nuclei in our study material and also determined whether those SC-beta cells expressed $\mathrm{Ki}-67$ as a marker of proliferation. The median SUR1-mutant SC-beta cell nucleus was $38 \%$ larger ( 47.6 vs $34.3 \mu \mathrm{m}^{2}, p=0.0005$ ) when the cell co-expressed $\mathrm{Ki}-67$, and $14 \%$ larger when the cell did not co-express Ki-67 (41.7 vs $36.6 \mu \mathrm{m}^{2}, p=$ diameter displayed. (e) Quantification of the surface area of all nuclei assigned to insulin-positive cells $(n=8236-9011)$ and all nuclei assigned to insulin-positive cells that co-stain with Ki-67 ( $n=59-98)$. (f) The percentage of nucleomegalic insulin-positive cells out of all insulin-positive cells in the individual grafts. Data presented as mean \pm SEM (except in e) from SC-islet grafts derived from one SUR1-mutant clone (red bars) and one SUR1-corrected clone (blue bars). Each data point in (b, c, f) represents population-wide characteristics of independent graft explants. (e) Data pooled from four individual SUR1-corrected (Corr.) and SUR1mutant (Mut.) grafts and presented as violin plot displaying range, median and interquartile range of the surface areas and approximate distribution. $(\mathbf{b}, \mathbf{c}, \mathbf{e}, \mathbf{f})$ Welch's unequal variances $t$ test. ${ }^{*} p<0.05 ; * * p<0.01$; $* * * p<0.001$

0.0001) (Fig. 5e), compared with the median SUR1corrected SC-beta cell nucleus. We next determined the rate of SC-beta cell nucleomegaly by using nuclear area of $100 \mu \mathrm{m}^{2}$ as a cut-off. The SUR1-mutant grafts had 2.9-fold higher rate of SC-beta cell nucleomegaly than the SUR1-corrected grafts (36 out of 9011 vs 11 out of 8236 SC-beta cells nucleomegalic). This rate in individual grafts was higher in the SUR1-mutants but not statistically significant (Fig. 5f). A single nucleomegalic SCbeta cell from the SUR1-mutant grafts co-expressed Ki67, while none were observed in the SUR1-corrected SC-beta cells (ESM Fig. 5). 


\section{Discussion}

We created a novel model for the study of $\mathrm{K}_{\mathrm{ATP}} \mathrm{HI}$ by recapitulating the disease phenotype in vitro and in vivo with SCislets. Our approach has several advantages: differentiation of stem cells into SC-islets mimics normal development and enables the study of developmental effects of mutations in a reliable isogenic comparison. The use of human cells circumvents the inherent issues associated with SUR1 knockout mouse models arising from species differences [34-37], while the subcapsular transplantation techniques still allow in vivo studies. Furthermore, the automated segmentation pipeline used for morphometric analysis reduces analysis bias.

The in vitro differentiation of iPSCs to SC-islets offers a unique window to the antenatal effects of $\mathrm{K}_{\mathrm{ATP}}$-channel inactivation, which would be near impossible to address in clinical studies. We discovered that SC-islets generated from SUR1mutant iPSCs contained more SC-beta cells and fewer SCalpha cells compared with SUR1-corrected SC-islets. Earlier morphometric studies have provided conflicting results regarding the presence of increased beta cell mass in diffuse $\mathrm{K}_{\mathrm{ATP}} \mathrm{HI}$ islets, with one group reporting increased total insulin-positive area in sections [32], and others not detecting such a difference [30,38]. The data obtained with our individual cell-based analysis gives weight to the argument that $\mathrm{K}_{\mathrm{ATP}}$-channel inactivation increases beta cell mass in humans.

In this study, SUR1-mutant SC-beta cells exhibited a higher proliferation rate, which could explain the increased final mass of SC-beta cells, with increased beta cell lineage allocation during differentiation possibly contributing. Proliferation of beta cells is known to be greatly increased in focal $\mathrm{K}_{\mathrm{ATP}} \mathrm{HI}$ owing to inactivation of growth suppressing $\mathrm{p} 57^{\mathrm{KIP}}$ [39], and slightly increased in diffuse $\mathrm{K}_{\mathrm{ATP}} \mathrm{HI}$ because of an unknown mechanism [28-32]. Rodent studies have shown that sulfonylurea drug treatment increases the replicative potential of beta cells, also pointing to the role of the $\mathrm{K}_{\mathrm{ATP}}$-channel in this process [40, 41]. $\mathrm{K}_{\mathrm{ATP}}$-channel inactivation may lead to multiple intracellular perturbations that could explain the increased proliferation. These include at least the autocrine effect of secreted insulin through the insulin receptor [42], changes in signalling pathways due to altered metabolic flux as a consequence of increased energy demand [32, 43], activation of the nuclear factor of activated T-cells (NFAT)/ calcineurin pathway because of the constitutively high intracellular $\mathrm{Ca}^{2+}$ [44], and elevation of endoplasmic reticulum stress to a level that promotes proliferation [45]. In future studies, our model could be used to elucidate the relevance of these pathways for increased beta cell proliferation in diffuse $\mathrm{K}_{\mathrm{ATP}} \mathrm{HI}$.

The critical aspect of the $\mathrm{K}_{\mathrm{ATP}} \mathrm{HI}$ patient phenotype on the beta cell level is the constant secretion of insulin. Our SCislets demonstrate a 3.2-fold higher basal insulin secretion, in line with the 2.8 -fold difference seen in a study using
$\mathrm{K}_{\text {ATP }} \mathrm{HI}$ patient islets [4]. We could also replicate the inability of SUR1-mutant cells to respond to diazoxide. Recapitulating the disease phenotype in vitro combined with the fact that the SC-islets can be generated in large quantities highlights the possibility of using this model for screening of novel antihypoglycaemic drugs for $\mathrm{K}_{\mathrm{ATP}} \mathrm{HI}$.

On a systemic level, the patient phenotype is characterised by the failure to shut down insulin secretion when blood glucose falls below a threshold, which in a healthy person serves as the first-line safeguard against hypoglycaemia. This excess insulin secretion is sufficient to overcome the capacity of the counterregulatory machinery [46], particularly in a young infant, resulting in severe hypoglycaemia. The data from our in vivo model indicate that the SUR1-mutant SCislet grafts were potent enough in secreting insulin that they could lower the fasting glucose levels of the recipient mice. After induced hypoglycaemia the SUR1-mutant grafts replicated the most devastating feature of the disease phenotype by continuing to secrete high levels of insulin.

The increase in insulin-positive cells persisted in grafts in vivo after 4 months, even when the rate of proliferation lowered, which fits with the established finding of a reduction in the proliferation rate of beta cells after birth [47]. This suggests that the abnormal hormonal populations are maintained without the need for constant proliferation of the SCbeta cells. Interestingly, the insulin-positive cells in SUR1mutant grafts exhibited nucleomegaly, a classical histological diagnostic sign for diffuse $\mathrm{K}_{\mathrm{ATP}} \mathrm{HI}[33,38]$ in addition to a general shift in the size distribution towards larger nuclei [38]. The explanation for this phenomenon is unknown, but our data add evidence to the notion that nucleomegaly is not linked to proliferation but rather to the constitutive hyperfunctionality of the cells. Our finding that apoptosis is not increased in the SUR1-mutant SC-beta cells does not rule out the possibility that beta cell apoptosis would be responsible for the self-limitation of hyperinsulinaemia in patients; however, the lifespan of the grafted mice limits the usefulness of our model in answering questions regarding such long-term pathophysiology.

Another limitation of our model is that the differentiation protocol used in this study produces beta-like cells that lack full coupling of glucose metabolism and insulin secretion present in adult human beta cells. This is not a critical shortcoming as $\mathrm{K}_{\mathrm{ATP}} \mathrm{HI}$ is primarily a neonatal condition and neonates lack this coupling as well [48]. Furthermore, the corrected SC-islets gain the ability to control their insulin secretion in vivo. Nevertheless, the model could be further refined by taking advantage of recent advances in the differentiation protocols to generate more mature $\mathrm{SC}$-islets in vitro [49].

In conclusion, we show that patient-derived SUR1-mutant $\mathrm{SC}$-islets recapitulate the cardinal feature of $\mathrm{K}_{\mathrm{ATP}} \mathrm{HI}$, the dysregulated insulin secretion in vitro and in vivo, along with 
increase in beta cell mass and proliferation. Our model constitutes a valuable tool to use in future endeavours to improve the management of $\mathrm{CHI}$ and in studying the basic biology of hypersecretory beta cells.

Supplementary Information The online version contains peer-reviewed but edited supplementary material available at https://doi.org/10.1007/ s00125-020-05346-7.

Acknowledgements P. Miettinen (Stem cells and metabolism research programme, University of Helsinki, Finland) is thanked for her commentary on the manuscript. S. Eurola, J. Ustinov, H. Grym and A. Laitinen (Stem cells and metabolism research programme, University of Helsinki, Finland) are thanked for their technical assistance. Biomedicum Helsinki tissue service is thanked for their sample processing. VL is a member of the $\mathrm{MD} / \mathrm{PhD}$ programme and the doctoral programme for biomedicine of University of Helsinki.

Data availability Data collected for this manuscript are available upon reasonable request from the corresponding authors. The CellProfiler pipelines developed for this study are available upon request from VL.

Funding This research has been funded by grants from the Academy of Finland (Project grant no. 297466 and the Center of Excellence MetaStem no. 312437), the Novo Nordisk Foundation (nos 0005565 and 0057286), the Sigrid Jusélius Foundation and the Finnish Diabetes Foundation. VL has received personal funding from University of Helsinki MD/PhD programme, the Finnish Diabetes Foundation and the Finnish Medical Foundation. The funders had no role in the study design, reporting or data analysis.

Authors' relationships and activities The authors declare that there are no relationships or activities that might bias, or be perceived to bias, their work.

Contribution statement VL designed experiments, performed SC-islet differentiations, acquired and analysed the data, designed the image analysis pipelines and wrote the first version of the manuscript. JSV assisted with SC-islet differentiations and data acquisition, performed animal experiments and edited the manuscript. DB performed genome editing, assisted with SC-islet differentiations and data acquisition and edited the manuscript. $\mathrm{HI}$ and $\mathrm{HM}$ assisted in data acquisition and edited the manuscript. TB analysed data and edited the manuscript. TO conceived the study, provided resources and edited the manuscript. All authors approved the final version of the manuscript. VL and TO are the guarantors of this work

\section{References}

1. Ashcroft FM, Harrison D, Ashcroft SJ (1984) Glucose induces closure of single potassium channels in isolated rat pancreatic beta cells. Nature 312(5993):446-448. https://doi.org/10.1038/ 312446a0

2. Kapoor RR, Flanagan SE, Arya VB, Shield JP, Ellard S, Hussain K (2013) Clinical and molecular characterisation of 300 patients with congenital hyperinsulinism. Eur J Endocrinol 168(4):557-564. https://doi.org/10.1530/EJE-12-0673

3. Snider KE, Becker S, Boyajian L et al (2013) Genotype and phenotype correlations in 417 children with congenital hyperinsulinism. J
Clin Endocrinol Metab 98(2):355-363. https://doi.org/10.1210/jc. 2012-2169

4. Henquin JC, Nenquin M, Sempoux C et al (2011) In vitro insulin secretion by pancreatic tissue from infants with diazoxide-resistant congenital hyperinsulinism deviates from model predictions. J Clin Invest 121(10):3932-3942. https://doi.org/10.1172/JCI58400

5. Thomas PM, Cote GJ, Wohilk $\mathrm{N}$ et al (1995) Mutations in the sulfonylurea receptor gene in familial persistent hyperinsulinemic hypoglycemia of infancy. Science 268(April):426-429. https://doi. org/10.1126/science.7716548

6. Otonkoski T, Ämmälä C, Huopio H et al (1999) A Point Mutation Inactivating the Sulfonylurea Receptor Causes the Severe Form of Persistent Hyperinsulinemic Hypoglycemia of Infancy in Finland. Diabetes 48(February):408-415. https://doi.org/10.2337/diabetes. 48.2.408

7. Banerjee I, Salomon-Estebanez M, Shah P, Nicholson J, Cosgrove KE, Dunne MJ (2019) Therapies and outcomes of congenital hyperinsulinism-induced hypoglycaemia. Diabet Med 36(1):9-21. https://doi.org/10.1111/dme.13823

8. Meissner T, Wendel U, Burgard P, Schaetzle S, Mayatepek E (2003) Long-term follow-up of 114 patients with congenital hyperinsulinism. Eur J Endocrinol 149(1):43-51. https://doi.org/10. 1530/eje.0.1490043

9. Adzick N, De Leon DD, States LJ et al (2019) Surgical Treatment of Congenital Hyperinsulinism: Results from 500 Pancreatectomies in Neonates and Children. J Pediatr Surg 54(1):27-32. https://doi. org/10.1016/j.jpedsurg.2018.10.030

10. Beltrand J, Caquard M, Arnoux J-B et al (2012) Glucose metabolism in 105 children and adolescents after pancreatectomy for congenital hyperinsulinism. Diabetes Care 35(2):198-203. https:// doi.org/10.2337/dc11-1296

11. Arya VB, Senniappan S, Demirbilek H et al (2014) Pancreatic endocrine and exocrine function in children following near-total pancreatectomy for diffuse congenital hyperinsulinism. PLoS One 9(5):4-9. https://doi.org/10.1371/journal.pone.0098054

12. Seghers V, Nakazaki M, DeMayo F, Aguilar-Bryan L, Bryan J (2000) Sur1 Knockout Mice study of K ATP -independent pathways that regulate insulin secretion. J Biol Chem 275(13):92709277. https://doi.org/10.1074/jbc.275.13.9270

13. Miki T, Tashiro F, Iwanaga T et al (1997) Abnormalities of pancreatic islets by targeted expression of a dominant-negative K ATP channel. Cell Biol 94(October):11969-11973. https://doi.org/10. 1073/pnas.94.22.11969

14. Miki T, Nagashima K, Tashiro F et al (1998) Defective insulin secretion and enhanced insulin action in K ATP channel-deficient mice. Biochemistry 95(September):10402-10406. https://doi.org/ 10.1073/pnas.95.18.10402

15. Shiota C, Larsson O, Shelton K et al (2002) Sulfonylurea Receptor Type 1 Knock-out Mice Have Intact Feeding-stimulated Insulin Secretion despite Marked Impairment in Their Response to Glucose. J Biol Chem 277(October):37176-37183. https://doi.org/ 10.1074/jbc.M206757200

16. Takahashi K, Tanabe K, Ohnuki M et al (2007) Induction of pluripotent stem cells from adult human fibroblasts by defined factors. Cell 131(5):861-872. https://doi.org/10.1016/j.cell.2007.11.019

17. Park I-H, Arora N, Huo H et al (2008) Disease-specific pluripotent stem cells. Cell 134(5):877-886. https://doi.org/10.1016/j.cell. 2008.07.041

18. Ran FA, Hsu PD, Wright J, Agarwala V, Scott DA, Zhang F (2013) Genome engineering using the CRISPR-Cas9 system. Nat Protoc 8(11):2281-2308. https://doi.org/10.1038/nprot.2013.143

19. Saarimäki-Vire J, Balboa D, Russell MA et al (2017) An Activating STAT3 Mutation Causes Neonatal Diabetes through Premature Induction of Pancreatic Differentiation. Cell Rep 19(2):281-294. https://doi.org/10.1016/j.celrep.2017.03.055 
20. Balboa D, Saarimäki-Vire J, Borshagovski D et al (2018) Insulin mutations impair beta-cell development in a patient-derived iPSC model of neonatal diabetes. Elife 7:e38519. https://doi.org/10.7554/ eLife.38519

21. Guo D, Liu H, Ru A, Gao G, Nasir A (2017) Modeling Congenital Hyperinsulinism with ABCC8 - Deficient Human Embryonic Stem Cells Generated by CRISPR / Cas9. Sci Rep 7(3156):1-8. https:// doi.org/10.1038/s41598-017-03349-w

22. Achuta VS, Grym H, Putkonen N, Louhivuori V (2016) Metabotropic Glutamate Receptor 5 Responses Dictate Differentiation of Neural Progenitors to NMDA-Responsive Cells in Fragile X Syndrome. Dev Neurobiol 77(July):438-453. https:// doi.org/10.1002/dneu.22419

23. Rezania A, Bruin JE, Arora P et al (2014) Reversal of diabetes with insulin-producing cells derived in vitro from human pluripotent stem cells. Nat Biotechnol 32(11):1121-1133. https://doi.org/10. 1038/nbt.3033

24. Pagliuca FW, Millman JR, Gürtler M et al (2014) Generation of Functional Human Pancreatic $\beta$ Cells In Vitro. Cell 159(2):428439. https://doi.org/10.1016/j.cell.2014.09.040

25. Nostro MC, Sarangi F, Yang C et al (2015) Efficient generation of NKX6-1+ pancreatic progenitors from multiple human pluripotent stem cell lines. Stem Cell Rep 4(4):591-604. https://doi.org/10. 1016/j.stemcr.2015.02.017

26. Vegas AJ, Veiseh O, Gürtler M et al (2016) Long-term glycemic control using polymer-encapsulated human stem cell-derived beta cells in immune-competent mice. Nat Med 22(3):306-311. https:// doi.org/10.1038/nm.4030

27. McQuin C, Goodman A, Chernyshev V et al (2018) CellProfiler 3.0: Next-generation image processing for biology. PLoS Biol 16(7):e2005970. https://doi.org/10.1371/journal.pbio.2005970

28. Kassem SA, Ariel I, Thornton PS, Scheimberg I, Glaser B (2000) Beta-Cell Proliferation and Apoptosis in the Developing Normal Human Pancreas and in Hyperinsulinism of Infancy. Diabetes 49(8):1325-1333. https://doi.org/10.2337/diabetes.49.8.1325

29. Lovisolo S, Mendonca B, Della Manna T, Saldiniva P, Zerbini M (2010) Congenital Hyperinsulinism in Brazilian Neonates: A Study of Histology, KATP Channel Genes, and Proliferation of $\beta$ Cells. Pediatr Dev Pathol 13(5):375-384. https://doi.org/10.2350/08-120578.1

30. Salisbury RJ, Han B, Jennings RE et al (2015) Altered phenotype of beta-cells and other pancreatic cell lineages in patients with diffuse congenital hyperinsulinism in infancy caused by mutations in the ATP-sensitive K-channel. Diabetes 64(9):3182-3188. https://doi. org $10.2337 / \mathrm{db} 14-1202$

31. Szymanowski M, Estebanez MS, Padidela R et al (2016) mTOR Inhibitors for the Treatment of Severe Congenital Hyperinsulinism: Perspectives on Limited Therapeutic Success. J Clin Endocrinol Metab 101(12):4719-4729. https://doi.org/10.1210/jc.2016-2711

32. Li C, Ackermann AM, Boodhansingh KE et al (2017) Functional and Metabolomic Consequences of ATP-dependent Potassium Channel Inactivation in Human Islets. Diabetes 66(January): db170029-db171913. https://doi.org/10.2337/db17-0029

33. Han B, Newbould M, Batra G et al (2016) Enhanced islet cell nucleomegaly defines diffuse congenital hyperinsulinism in infancy but not other forms of the disease. Am J Clin Pathol 145(6):757768. https://doi.org/10.1093/ajcp/aqw075

34. Balboa D, Otonkoski T (2015) Human pluripotent stem cell based islet models for diabetes research. Best Pract Res Clin Endocrinol Metab 29(6):899-909. https://doi.org/10.1016/j.beem.2015.10.012
35. Nair G, Hebrok M (2015) Islet formation in mice and men: Lessons for the generation of functional insulin-producing $\beta$-cells from human pluripotent stem cells. Curr Opin Genet Dev 32:171-180. https://doi.org/10.1016/j.gde.2015.03.004

36. Cabrera O, Berman DM, Kenyon NS, Ricordi C, Berggren P-O, Caicedo A (2006) The unique cytoarchitecture of human pancreatic islets has implications for islet cell function. Proc Natl Acad Sci U S A 103(7):2334-2339. https://doi.org/10.1073/pnas.0510790103

37. Rodriguez-Diaz R, Molano RD, Weitz JR et al (2018) Paracrine Interactions within the Pancreatic Islet Determine the Glycemic Set Point. Cell Metab 27(3):549-558.e4. https://doi.org/10.1016/j. cmet.2018.01.015

38. Rahier J, Falt K, Muntefering H, Becker K, Gepts W, Falkmer S (1984) The basic structural lesion of persistent neonatal hypoglycaemia with hyperinsulinism: deficiency of pancreatic D cells or hyperactivity of B cells? Diabetologia 26(4):282-289. https://doi.org/10.1007/BF00283651

39. Kassem S, Ariel I, Thornton PS et al (2001) p57 KIP2 Expression in Normal Islet Cells and in Hyperinsulinism of Infancy. Diabetes 50(12):2763-2769. https://doi.org/10.2337/diabetes.50.12.2763

40. Popiela H, Moore W (1991) Tolbutamide stimulates proliferation of pancreatic beta cells in culture. Pancreas 6(4):464-469. https://doi. org/10.1097/00006676-199107000-00014

41. Guiot Y, Henquin J, Rahier J (1994) Effects of glibenclamide on pancreatic beta-cell proliferation in vivo. Eur J Pharmacol 261(12):157-161. https://doi.org/10.1016/0014-2999(94)90314-x

42. Okada T, Chong WL, Hu J et al (2007) Insulin receptors in $\beta$-cells are critical for islet compensatory growth response to insulin resistance. Proc Natl Acad Sci U S A 104(21):8977-8982. https://doi. org/10.1073/pnas.0608703104

43. Porat S, Weinberg-corem N, Tornovsky-babaey S et al (2010) Article Control of Pancreatic b Cell Regeneration by Glucose Metabolism. Cell Metab 13(4):440-449. https://doi.org/10.1016/j. cmet.2011.02.012

44. Dai C, Hang Y, Shostak A et al (2017) Age-dependent human $\beta$ cell proliferation induced by glucagon-like peptide 1 and calcineurin signaling. J Clin Invest 127(10):3835-3844. https://doi.org/10. 1172/JCI91761

45. Sharma RB, O'Donnell AC, Stamateris RE et al (2015) Insulin demand regulates $\beta$ cell number via the unfolded protein response. J Clin Invest 125(10):3831-3846. https://doi.org/10.1172/ JCI79264

46. Cryer PE (2008) The barrier of hypoglycemia in diabetes. Diabetes 57(12):3169-3176. https://doi.org/10.2337/db08-1084

47. Gregg BE, Moore PC, Demozay D et al (2012) Formation of a Human Beta-Cell Population within Pancreatic Islets Is Set Early in Life. J Clin Endocrinol Metab 97(9):3197-3206. https://doi.org/ 10.1210/jc.2012-1206

48. Henquin J-C, Nenquin M (2017) Immaturity of insulin secretion by pancreatic islets isolated from one human neonate. J Diabetes Investig 9(2):270-273. https://doi.org/10.1111/jdi.12701

49. Velazco-cruz L, Song J, Maxwell KG et al (2019) Acquisition of Dynamic Function in Human Stem Cell-Derived Beta Cells. Stem Cell Rep 12(2):351-365. https://doi.org/10.1016/j.stemcr.2018.12. 012

Publisher's note Springer Nature remains neutral with regard to jurisdictional claims in published maps and institutional affiliations. 